\title{
Importância do cooperativismo de crédito para o desenvolvimento do agronegócio
}

\author{
Andressa Michels* \\ Joice Coletti Luna** \\ Daniela Rinaldi****
}

\begin{abstract}
Resumo
Buscou-se identificar a relevância dos produtos e serviços oferecidos pelas cooperativas de crédito para o setor de agronegócios no desenvolvimento das propriedades, além de identificar os efeitos gerados após a injeção de créditos específicos no desenvolvimento das propriedades rurais, os processos e a visão da cooperativa em relação aos agricultores. Os dados coletados evidenciaram que o cooperativismo de crédito se apresenta como uma alternativa considerável para o desenvolvimento das propriedades rurais e, consequentemente, para o desenvolvimento regional. Maior procura se dá pelos financiamentos e empréstimos pelos agricultores para a continuidade ao desenvolvimento de suas propriedades, investindo nas culturas e nos implementos.
\end{abstract}

Palavras-chave: cooperativas de crédito; agricultores; desenvolvimento regional; propriedades rurais.

* Bacharela em Ciências Contábeis pela Faculdade de Itapiranga (FAI) (Atual UCEFF) e mestra em Ciências Contábeis pela Universidade Regional de Blumenau (FURB). Docente na Universidade do Oeste de Santa Catarina (UNOESC).E-mail: andressamichels91@gmail.com

** Acadêmica de Ciências Contábeis da Universidade do Oeste de Santa Catarina (UNOESC). E-mail: joicecoletti001@hotmail.com

**** Acadêmica de Ciências Contábeis da Universidade do Oeste de Santa Catarina (UNOESC). E-mail: daanirinaldi@gmail.com

http://dx.doi.org/10.5335/rtee.v26i55.12262

Submissão: 10/02/2021. Aceite: 28/04/2021. 


\section{Introdução}

Desde seus primeiros movimentos, é visível que cooperativas sempre mantiveram uma relação próxima com os agricultores. Essa harmonia proporcionou muitas vantagens para ambos os lados. É notável a participação das instituições no movimento da economia, essencialmente em pequenos municípios, como é o caso do extremo oeste catarinense, no qual se observa que o cooperativismo e a agricultura familiar têm grande expressão, e essa união resultou em mais desenvolvimento. Trabalhando coletivamente e com cooperação, os agricultores tiveram acesso a um crédito menos evasivo, trazendo a oportunidade de crescimento. Com isso, as cooperativas de crédito também conquistaram seu lugar ao tratar seus cooperados de forma especial, aproximando-os da instituição e mostrando a importância de cada sócio, conseguiram trilhar um caminho com espaço para muitos anos de crescimento.

Em pequenos e firmes passos, as cooperativas estão ganhando cada vez mais espaço. A disponibilidade de taxas mais acessíveis, ponto forte desse ramo, um amplo portfólio de produtos e serviços, a preocupação com seus associados, somados a um atendimento próximo e personalizado, fazem com que as instituições tenham base para suprir as necessidades dos seus sócios e concorrer com os bancos já consolidados.

Uma das bases para o crescimento das cooperativas de crédito foi a grande aceitação, pois, no início, trazia em suas ações a proteção para grupos menos valorizados. Staub, Fuhrmann e Staub (2016) definiram o cooperativismo como uma iniciativa que reúne pessoas, entidades ou empresas que têm um objetivo em comum, unindo forças para defender os interesses do grupo e estimular a melhoria técnica, profissional e social de seus cooperados, e a agricultura apresenta os mesmos traços. Prova disso é a criação das associações de agricultores que surgiram no extremo oeste catarinense, no ano de 1970, com o intuito de defender a classe do trabalhador rural frente a todas as dificuldades da época, os agricultores uniram-se por objetivos em comum, principalmente por melhores condições de vida e uma sociedade mais igualitária, acreditando na força coletiva (FARIAS, 2010).

Um dos principais pontos positivos da agricultura familiar é a produção de alimentos totalmente naturais. Sua contribuição mais importante é na geração de alimentos básicos para as famílias brasileiras, com isso, surgiram muitas estratégias com os objetivos de estabelecer a segurança alimentar e impulsionar a 
produção agrícola, setor que ainda enfrenta algumas adversidades, mas que resiste (SERENINI; MALYSZ, 2015). A produção de uma família de agricultores não representa grandes números para os índices nacionais, mas o movimento de todos os integrantes desse setor tem relevância significativa para a economia, principalmente em caráter municipal, onde a força dos movimentos dessa divisão tem maior expressão.

O associativismo vem crescendo de mãos dadas com o agronegócio desde muito tempo. Mumic, Aguiar e Livramento (2016) definem as cooperativas como a união de pessoas, de forma voluntária, para alcançar um objetivo de interesse coletivo. Nesse sistema, os associados possuem direitos e deveres iguais.

Com base na concentração de cooperativas de crédito no município de São Miguel do Oeste e no sistema praticado pelas instituições, em que se destaca as acessíveis taxas de crédito, levanta-se o questionamento: qual a influência e a relevância, levando em conta produtos e serviços, das cooperativas de crédito para os agricultores e as propriedades rurais?

Dessa forma, o objetivo geral é identificar a relevância dos produtos e serviços, oferecidos pelas cooperativas de crédito, para o setor de agronegócios, no desenvolvimento das propriedades. Para o desenvolvimento deste trabalho, têm-se os seguintes objetivos específicos: a) realizar a caracterização da amostra pesquisada; b) verificar quais os créditos específicos mais utilizados; c) identificar os efeitos gerados após a injeção do crédito no desenvolvimento das propriedades; d) demonstrar a importância das cooperativas de crédito no cenário do agronegócio.

A literatura aponta estudos que buscaram verificar a importância da existência de crédito para o desenvolvimento local e regional (GUISO; SAPIENZA; ZINGALES, 2004; MISSIO; JAYME JR.; OLIVEIRA, 2010; OÑATE; LIMA, 2012), a evolução das cooperativas no setor financeiro e o impacto sobre a renda dos municípios (PORTO; FERREIRA, 2014). De modo geral, os achados reforçam a máxima de que essas entidades são de fundamental importância para o desenvolvimento do ambiente em que se inserem.

Não se observam, no entanto, estudos que tenham analisado aspectos envolvendo as cooperativas de créditos e os tomadores de empréstimos do agronegócio, especificamente. Justifica-se, portanto, a realização do presente estudo, uma vez que viabiliza a comparação de desenvolvimento de pequenos e grandes agricultores com o auxílio de créditos concedidos, específicos para a agricultura, visando captar a importância desse ramo para os beneficiados. 


\section{Cooperativismo - história no Brasil e no mundo}

Hoje, as instituições cooperativas possuem maior visibilidade e importância no Brasil e no mundo, mas sua história tem uma longa caminhada. O cooperativismo iniciou após a Revolução Industrial, no século XVIII, na Inglaterra, como uma doutrina que pregava a colaboração e a associação de pessoas com interesses para obter vantagens em suas atividades econômicas. Diante da situação econômica daquela época, com baixos salários, longa jornada de trabalho e dificuldades que a sociedade enfrentava, começaram a surgir lideranças e associações que cresceram e ganharam força com o passar dos anos, amenizando assim os efeitos do capitalismo (STAUB; FUHRMANN; STAUB, 2016).

Vinte e sete homens e uma mulher uniram-se com o objetivo de construir seu próprio armazém para fazer a compra de alimentos em grandes quantidades para conseguir melhores preços, com o acordo de divisão igualitária entre todos os cooperados (PORTAL DO COOPERATIVISMO FINANCEIRO, 2016b). Ali surgia a Sociedade dos Probos de Rochdale, conforme dados do site da Organização das Cooperativas do Brasil, essa foi a primeira cooperativa moderna do mundo. Nesse momento, foram definidos os princípios morais e de conduta, considerados até hoje a base do cooperativismo. Em 1848, possuía 140 sócios; 12 anos depois, atingiu a marca de 3.450 sócios, totalizando o capital de 152 mil libras (PORTAL DO COOPERATIVISMO FINANCEIRO, 2016b).

[...] em 1844, com o exemplo que se tornou famoso e mundialmente conhecido - a cooperativa dos pobres tecelões de Rochdale. Era na realidade o início da cooperação de consumidores que buscavam melhor qualidade de vida e solução para seus próprios problemas de desemprego e fome. Tentativas anteriores já haviam ocorrido sem sucesso devido a vários fatores ligados à falta de experiência gestionária das várias associações de auxílio mútuo, mas sobretudo, devido oposição governamental e empresarial, temerosa de qualquer atividade que pudesse levar a união dos trabalhadores e a protesto quanto às graves condições de trabalho no início do século XIX (PINHO; PALHARES, 2004, p. 33).

A Alemanha recebeu suas duas primeiras cooperativas em 1862, nas cidades de Renânia e Palatinado. Em um primeiro momento, não foram bem aceitas pela população local, mas, em 1900, as cooperativas de crédito já totalizavam 2.083 , com 265 mil sócios, naquela região. Já no Brasil, a primeira cooperativa de crédito surgiu em 1902, fundada pelo padre Theodor Amstad, chamou-se Sicredi Pioneira, com sua sede em Nova Petrópolis e continua até hoje em atividade (PORTAL DO COOPERATIVISMO FINANCEIRO, 2016a).

Teoria e Evidência Econômica - a. 26, n. 55, p. 244-271, jul./dez. 2020 
Também na Alemanha, Friedrich Wilhelm Raiffeisen constituiu em 1862, em Anhausen, e em 1864, em Heddesdorf, ambas na região da Renânia Palatinado, as cooperativas de crédito rural, à época chamadas de Loan Societies. Após um período inicial de baixa adesão, em 1900, já havia 2.083 cooperativas de crédito na região, que seguiam o modelo Raiffeisen, totalizando 265 mil associados (PORTAL DO COOPERATIVISMO FINANCEIRO, 2016a).

Vê-se que a essência do cooperativismo traz um cunho social. Ele teve início entre a população oprimida, entre uma tentativa e outra de mudar sua condição de vida, de todos os esforços envolvidos, chega-se a um fim proveitoso de todas as partes envolvidas (ULHARUZO, 2014).

As raízes das ideias de cooperativismos surgiram bem antes da colonização do Brasil, mas foi em 1889 que a primeira cooperativa do país foi criada. Uma cooperativa de consumo na cidade de Ouro Preto, Minas Gerais. Já no século XX, em 1902 surgia a primeira cooperativa de crédito do país no Rio Grande do Sul, região onde há um grande número destas; no ano de 1906, começaram a surgir no país as primeiras cooperativas agropecuárias (SICOOB CECREMEF, 2019).

Em 1971, a Lei no 5.764/1971 disciplinou a criação de cooperativas no Brasil. Entretanto, a legislação limitou a autonomia dos cooperados, interferindo na criação, no funcionamento e na fiscalização dessas instituições. Porém, esse problema só foi resolvido com a Constituição Federal de 1988, que coibiu a interferência do Estado e deu às cooperativas o poder de autogestão (BRASIL, 1971).

Muitas entidades relacionadas ao cooperativismo ocupam espaço no mercado, com o objetivo de apoiar, prestar serviços e estimular o desenvolvimento, algumas delas estão em atividade há décadas, como é o caso do Conselho Mundial das Cooperativas de Crédito (World Council of Credit Unions - WOCCU), criado em 1971, contando com filiadas em 84 países, que representam mais de 40 mil cooperativas de crédito. Suas ações envolvem divulgação de matérias direcionadas às cooperativas, apoio à criação de novas instituições, formulação e debate de normas, regimentos, apoio ao desenvolvimento, entre muitos outros movimentos (PINHEIRO, 2008).

A Organização das Cooperativas Brasileiras (OCB) também tem grande expressão, foi criada em 2 de dezembro de 1969, durante o IV Congresso Brasileiro de Cooperativismo, passando a defender os interesses do cooperativismo no Brasil. Essa organização é sem fins lucrativos, com neutralidade política e religiosa, alinhada aos ideais históricos do cooperativismo. Com a filiação da OCB com a Aliança Cooperativa Internacional, a área cooperativa começou a trocar experiências em 
parâmetros internacionais, trazendo objetividade, transparência e foco, buscando evidenciar os pontos fortes do cooperativismo (OCB, 2019).

\section{Cooperativas de crédito}

A cooperação é um ato que se observa nas diversas relações entres os seres humanos, é uma característica comum o ato de cooperar a fim de desenvolver alguma atividade específica, otimizar processos que são mais complexos ou que demandam um maior gasto de recursos, sejam eles energéticos ou temporais.

Conforme Ulharuzo (2014, p. 18),

[...] as cooperativas são então uma forma elaborada de cooperação, onde seus membros buscam um fim determinado através da troca de recurso diversos. Oriunda de movimentos sociais das classes mais flageladas, hoje seus preceitos estão disseminados nos diversos níveis culturais e econômicos, e tem como escopo final as mais diversas finalidades.

A política nacional do cooperativismo classificou as cooperativas de crédito em três principais grupos: cooperativas singulares, que são constituídas por no mínimo vinte pessoas e aceitam pessoas jurídicas sem fins lucrativos ou com atividades relacionadas às de pessoas físicas; cooperativas constituídas por no mínimo três singulares são definidas como centrais ou federações de cooperativas; e, por fim, as confederações das cooperativas centrais são formadas por no mínimo três cooperativas centrais iguais ou de diferentes modalidades (BACEN, 2019).

Um dos principais recursos utilizados pelas cooperativas para se estabelecerem e crescerem é o capital social, sendo um pré-requisito para ingressar na instituição. Fortunato (2017) aborda que o capital social, ou cota de participação, possibilita a geração de serviços para os associados, seu montante impulsiona as operações de crédito e proporciona independência, com isso, a instituição depende cada vez menos de recursos vindos de terceiros e oferece taxa de juros mais atrativas. Os cooperados tornam-se donos e usuários, recebendo espaço para opinar na gestão e usufruir dos produtos. Cada associado leva consigo o poder de um voto, e isso independe do valor em sua cota capital.

As entidades cooperativas não visam lucros, então, as sobras são divididas entre os seus associados, geralmente o critério de divisão envolve as movimentações registradas em cada conta corrente durante o ano. Além das sobras, os sócios devem receber também uma remuneração pelo seu montante em cota capital, a 
legislação diz que a remuneração é limitada ao máximo de $12 \%$ ao ano (STAUB; FUHRMANN; STAUB, 2016).

De acordo com o site do Banco Central do Brasil (2019), todos os depósitos são protegidos pelo Fundo Garantidor do Cooperativismo de Crédito (FGCoop). O fundo tem o objetivo de proteger os valores depositados em contas correntes, o valor máximo que o FGCoop assegura é o valor de duzentos e cinquenta mil reais por CPF, em casos de intervenção ou liquidação extrajudicial nessas instituições.

Em 2017, existiam 1.006 cooperativas de crédito em funcionamento, sendo 967 cooperativas singulares, 37 cooperativas centrais e 2 bancos cooperativos. Todas movimentaram $2,97 \%$ do saldo das operações de crédito, resultando em $\mathrm{R} \$ 92,25$ bilhões no final do mesmo ano. O Sul se destaca com a maior participação das instituições e também pelo maior crescimento referente aos movimentos das pessoas jurídicas, de 2,1\% de participação de mercado, em 2005, para 16,7\% em 2017 (BACEN, 2018).

\section{A importância da cooperativa de crédito na sociedade}

Juntamente com a cooperação vem o progresso, suportado por alguns pilares, o preparo da população somado com o potencial da região, assistida pela instituição. A cooperativa é vista como um grande apoio no núcleo social, incentivando o empreendedorismo e apoiando o meio onde está inserida, auxiliando na melhora da qualidade de vida dos habitantes, sendo eles associados ou não.

Meinen (2016) aborda o cooperativismo como nada mais que uma organização democrática com o objetivo de solucionar os problemas compartilhados pelos envolvidos, o próprio Índice de Desenvolvimento Humano (IDH) é utilizado como forma de mensuração para evidenciar os benefícios de uma cooperativa no lugar onde está inserida, é comprovado que onde há cooperativas o IDH é superior às demais áreas.

As cooperativas possuem como característica a participação em vários projetos sociais, por ter sua formação entre as massas menos favorecidas, o apoio direcionado aos pequenos grupos continua sendo uma preocupação, esses movimentos vem beneficiando milhares de pessoas, um exemplo de projeto é o dia $\mathrm{C}$ de Cooperar, que surgiu em 2009, desenvolvido pelo Serviço Nacional de Aprendizagem do Cooperativismo (SESCOOP). O projeto acontece todos os anos e tem o objetivo de incentivar ações sociais e voluntárias, no dia $\mathrm{C}$, são registrados vários movimentos e 
doações por parte das cooperativas cadastradas, que se localizam em várias regiões do país (SESCOOP, 2015).

As cooperativas são movidas por ações diferenciadas, a proposta sempre foi voltada para a sociedade. Suas atitudes são formadas com base na união e no compartilhamento direcionados para o benefício da sociedade, esbanjando coletividade e força em prol do desenvolvimento econômico social. Costa e Valdisser (2017) destacam o atendimento personalizado oferecido pelas instituições, que tem como objetivo encaixar-se com cada perfil de associados e, também, as tarifas reduzidas como diferenciais positivos em relação às demais instituições financeiras.

As formas de trabalho e apresentação já foram bem acolhidas pela sociedade, trabalhar com uma instituição que oferece atendimento que aproxime e simplifique para o sócio os processos cheios de burocracias, com uma grande cartela de produtos personalizados e de boa qualidade e que faz questão de prezar a união, atrai os futuros associados e faz permanecer os já sócios.

As instituições foram abraçadas pela sociedade, elas estão presentes em grande parte dos eventos promovidos pela cidade onde se localizam, o apoio vai muito além do financeiro, percebe-se uma mobilização de sócios, dirigentes e colaboradores, que resulta em maior engajamento (MEINEN, 2016).

\section{Agricultura familiar}

Segundo a Lei no 11.326 , é considerada agricultura familiar a área do empreendedorismo rural que não passe de quatro módulos fiscais, a mão de obra precisa necessariamente ser da própria família, a renda predominante origina-se das atividades desenvolvidas na propriedade e a gestão provém do próprio núcleo familiar (BRASIL, 2006).

Buainain (2006) relata que as atividades agrícolas no Brasil começaram desde seu descobrimento em 1500, com a ação dos colonizadores que, em seus navios, trouxeram animais e vegetais e desenvolveram a atividade de produção agrícola. Nos anos 1960 e 1970, houve uma grande transformação no setor com a inclusão de máquinas, adubos e defensivos químicos, marcando a modernização da agricultura brasileira. Hoje, a agricultura tem grande força em nível de mundo e tornou-se a fonte de matéria-prima e alimento de muitos países.

A agricultura familiar encontra-se espalhada em todo o território nacional. Nos municípios do país, a participação dos estabelecimentos familiares no total de 
estabelecimentos é superior a 60\%. Nas Regiões Sul e Nordeste, os estabelecimentos familiares superam $80 \%$ do total. É comum caracterizar a agricultura familiar como um setor atrasado dos pontos de vista econômico, tecnológico e social, voltado fundamentalmente para a produção de produtos alimentares básicos e com uma lógica de produção de subsistência (BUAINAIN, 2006).

Para Andrade e Alves (2013), a agricultura é extremamente diversificada no Brasil, incluindo tanto famílias que vivem e exploram minifúndios em condições de extrema pobreza como produtores inseridos no moderno agronegócio, que logram gerar renda superior. A diferenciação da agricultura familiar está associada com a própria formação dos grupos ao longo da história, a cultura que cada uma vive e a experiência profissional e de vida. Essa diferença está associada também à inserção desses grupos nos diversos tipos de paisagens agrárias existentes e à atividade econômica desenvolvida. Grande parte dessa diferença se dá em relação às potencialidades e às restrições associadas à disponibilidade de recursos e de aprendizados adquiridos.

Conforme Buainain (2006, p. 17),

[...] a agricultura familiar pode e deve se integrar às cadeias agroindustriais mais dinâmicas do País. Em alguns casos ela poderia se constituir na base principal da dinamização de subsistemas agroindustriais já existentes ou na criação de novos subsistemas, neste último caso pensando-se especialmente em nichos de mercado ou em canais alternativos de comercialização.

$\mathrm{Na}$ agricultura familiar, encontram-se vários obstáculos, entre eles: desenvolvimento e repasse de tecnologias adequadas para os agricultores, capacitação, financiamento, políticas públicas voltadas para a transformação estrutural do setor, entre outros que serão abordados adiante. $O$ futuro depende da capacidade e da possibilidade do aproveitamento das oportunidades decorrentes das possíveis vantagens associadas à organização familiar da produção (ANDRADE; ALVES, 2013). Hoje, ela ocupa um importantíssimo espaço no desenvolvimento sustentável do país, pela sua contribuição econômica. No Brasil, há mais de 4 milhões de estabelecimentos familiares rurais. A renda do setor responde por 33\% do Produto Interno Bruto (PIB) agropecuário e por $74 \%$ da mão de obra empregada no campo (BUAINAIN, 2006). 


\section{Recursos voltados para a agricultura}

Ribeiro, Nascimento e Silva (2013) ressaltaram a relação entre os agricultores e o cooperativismo. O ato de cooperação tem raízes na solidariedade entre os agricultores em simples trocas de favores, como, por exemplo, nas colheitas, para ultrapassar dificuldades como eventos naturais e as precárias condições. A agricultura é uma das principais atividades econômicas do país, e o governo, sabendo disso, criou várias formas de estimular e fomentar essa área, privilegiando desde os grandes produtores até o pequeno agricultor familiar.

O crédito rural surgiu no país em 1935, e sua gestão ficou por conta do Banco do Brasil por 30 anos, por meio da Carteira de Crédito Agrícola e Industrial, em 1965, a competência passou para o Banco Central, com a prática do Sistema Nacional de Crédito Rural. Atualmente, as normas que regem esse segmento são aprovadas pelo Conselho Monetário Nacional (BACEN, 2019).

Conforme Menezes e Lajus (2015), o cooperativismo de crédito pode ser usado como um meio de apoio, promovendo a disponibilização de recursos a custos mais baixos em negócios com maior identificação do seu local de abrangência. $\mathrm{O}$ crédito como desenvolvimento apresenta um grande potencial para o desenvolvimento de toda sociedade.

Segundo o plano Safra da agricultura familiar, desenvolvido pela Secretaria Especial de agricultura familiar e do desenvolvimento agrário (2017), o plano Safra 2017/2020 é a junção de dez eixos para dar mais força ao pequeno produtor. Dentre os eixos, destaca-se o Programa Nacional de Fortalecimento da Agricultura Familiar (Pronaf), essa modalidade de empréstimo fornece juros mais baixos do mercado, intercalando de $0,5 \%$ a $5,5 \%$ ao ano. É destinado, principalmente, para o custeio de alimentos que fazem parte da cesta básica brasileira - arroz, feijão, laranja, entre outros. Conforme Carneiro (1997), o Pronaf tem raízes europeias, principalmente da França, que, no pós-guerra, voltou seus cuidados para a agricultura familiar, buscando modernizar a produção agrícola e a sociedade rural.

O projeto resultou em bons frutos, segundo dados do Banco Central do Brasil (2018), a procura maior no crédito rural e agroindustrial e empréstimos não consignados em cooperativas de crédito teve um aumento significativo. Em 2005, registrou-se 6,35\% de participação das instituições no mercado de pessoas físicas, em 2017 aumentou para 14,15\%, evidenciando a aprovação e a aderência por parte dos agricultores. 
Desenvolvido em 1996, o Pronaf foi um divisor de águas para a agricultura familiar. Moraes, Medeiros e Matte Junior (2018) consideram o Pronaf como uma vitória dos agricultores e uma união com os sindicatos, beneficiando principalmente a classe da agricultura familiar, tendo como objetivo incentivar a competitividade nesse meio.

Além do crédito mais barato, o governo também garantiu a segurança dos agricultores, oferecendo seguros para as plantações e contra a queda brusca de preços no mercado, como o Garantia-Safra e o Programa de Garantia de Preços da Agricultura Familiar. No ano de 2017, foi regulamentada a lei voltada para a agricultura familiar, Lei n⿳0 9.064, instituindo o Cadastro Nacional da Agricultura Familiar (CAF), que promove a identificação desses agricultores por meio de requisitos estabelecidos, criando um controle mais rígido, destinando ao público certo os estímulos e apoios já citados (BRASIL, 2017).

Conforme a Secretaria de Agricultura Familiar e Cooperativismo (2014), para os grandes agricultores, o governo criou o Plano Agrícola e Pecuário, implantado entre 2013 e 2014, esse plano amplia a disponibilidade ao crédito agrícola para o incentivo da produção, apoia a comercialização dos produtos, estimulando e assegurando o produtor, incentivando a inovação tecnológica, fomentando o aumento de produção.

\section{Estudos correlatos}

Para aprofundamentos da pesquisa, utilizou-se as bases de dados da Plataforma de Periódicos da Coordenação de Aperfeiçoamento de Pessoal de Nível Superior (Capes), por meio das palavras-chave: "cooperativismo", "agricultura familiar", "cooperativas de crédito", "desenvolvimento e crédito rural”. Artigos estes que apresentam estudos já realizados envolvendo tais temáticas; a seguir, no Quadro 1 , relatam-se os três estudos que abordam o tema objeto da pesquisa. 
Quadro 1 - Estudos correlatos

\begin{tabular}{|c|c|c|}
\hline Autor/Ano & Objetivo geral & Principais resultados \\
\hline $\begin{array}{l}\text { Andrade } \\
\text { e Alves } \\
(2013)\end{array}$ & $\begin{array}{l}\text { Tem como objetivo identificar e } \\
\text { analisar as principais práticas, } \\
\text { dificuldades e oportunidades } \\
\text { encontradas pelos cooperados } \\
\text { de uma cooperativa de agri- } \\
\text { cultores familiar da cidade de } \\
\text { Rubiataba, estado de Goiás, } \\
\text { denominada Cooperativa Mis- } \\
\text { ta de Agricultores Familiares } \\
\text { de Rubiataba (COOMAFAR). }\end{array}$ & $\begin{array}{l}\text { O estudo concluiu que os princípios cooperativistas da cooperativa } \\
\text { que foi analisada precisam estar mais presentes, colocados em prática } \\
\text { para com os seus membros. Notou-se que, por parte da diretoria ad- } \\
\text { ministrativa da cooperativa, faltam iniciativas em proporcionar aos agri- } \\
\text { cultores cursos de qualificação, nas áreas administrativas e técnicas, } \\
\text { com vistas a superar as dificuldades encontradas por eles, a fim de } \\
\text { obter um melhor desempenho nas atividades produtivas, desenvolven- } \\
\text { do as propriedades rurais que fazem parte dela. Os autores chegaram } \\
\text { à conclusão de que os cooperados estão dispostos a produzir mais e } \\
\text { se aperfeiçoar, buscando recursos e iniciativas vindos da cooperativa. }\end{array}$ \\
\hline $\begin{array}{l}\text { Ulharuzo } \\
(2014)\end{array}$ & $\begin{array}{l}\text { Analisar a contribuição das } \\
\text { cooperativas de crédito do } \\
\text { sistema Sicredi, em especial } \\
\text { a Sicredi Pioneira RS, para o } \\
\text { desenvolvimento endógeno } \\
\text { dos locais onde atuam. }\end{array}$ & $\begin{array}{l}\text { O estudo verificou que as cooperativas de crédito atuam no desenvolvi- } \\
\text { mento das regiões em que estão inseridas, principalmente por seu viés } \\
\text { cooperativista. Elas colaboram para o bem comum de seus associados, } \\
\text { gerando um benefício para o local onde estes estão inseridos. Concluí- } \\
\text { ram que as vantagens na escolha de uma cooperativa de crédito como } \\
\text { agente financeiro em relação a instituições financeiras normais para a } \\
\text { localidade em que seus associados residem são diversas, dentre elas, } \\
\text { a facilidade ao crédito, principalmente para a agricultura, pela diferen- } \\
\text { ciação de taxas no momento de captação de empréstimos e financia- } \\
\text { mentos. Além das sobras líquidas anuais, que são divididas entre seus } \\
\text { associados. Outro fator de destaque descrito no estudo é que nas coo- } \\
\text { perativas seus associados devem atuar e residir somente na região de } \\
\text { ação da sua cooperativa, dessa maneira, as riquezas produzidas são } \\
\text { utilizadas no financiamento de mais investimentos na região. Na análise } \\
\text { da região da Sicredi Pioneira RS, os autores relatam que ela passa por } \\
\text { um desenvolvimento que se sustenta pela diversidade em seus setores } \\
\text { econômicos atendidos e pela maior autonomia econômica que os pe- } \\
\text { quenos municípios apresentam. }\end{array}$ \\
\hline $\begin{array}{l}\text { Menezes } \\
\text { e Lajus } \\
(2015)\end{array}$ & $\begin{array}{l}\text { Compreender o cooperati- } \\
\text { vismo no século atual e a } \\
\text { sua relação com o desen- } \\
\text { volvimento; discutir o ganho } \\
\text { social que a Unicred Oeste } \\
\text { e Serra traz para a cidade de } \\
\text { Chapecó. }\end{array}$ & $\begin{array}{l}\text { Os autores concluíram que a Unicred, por meio de suas ações, con- } \\
\text { tribui para o desenvolvimento local e regional, já que os recursos são } \\
\text { utilizados na própria comunidade, agregando melhorias para os indiví- } \\
\text { duos, mesmo os que não são cooperados beneficiam-se indiretamente. } \\
\text { A pesquisa mostrou também que o caráter social do cooperativismo se } \\
\text { expressa por demonstrar que os financiamentos buscados pela maioria } \\
\text { dos associados se destinam a melhorias das suas condições de vida e } \\
\text { de trabalho, tanto pessoas físicas como jurídicas. Conforme os dados } \\
\text { encontrados pelos autores, tal fato está relacionado com a possibilidade } \\
\text { de obter menores taxas em comparação às praticadas pelo mercado, a } \\
\text { realização de operações entre seus pares e a garantia de que o resul- } \\
\text { tado financeiro (sobras) retorna para o próprio cooperado e não para } \\
\text { acionistas, como é feito no sistema bancário tradicional. Também se } \\
\text { destacou como importante a prática de oferta de taxas mais baixas que } \\
\text { as do mercado possibilitada pelo baixo custo da gestão, a pulverização } \\
\text { da concessão de empréstimos e a baixa inadimplência em comparação } \\
\text { com o sistema bancário. }\end{array}$ \\
\hline $\begin{array}{l}\text { Costa e } \\
\text { Valdisser } \\
(2017)\end{array}$ & $\begin{array}{l}\text { Estabelecer as principais di- } \\
\text { ferenças entre cooperativas } \\
\text { de crédito e os bancos co- } \\
\text { merciais, ampliando a visão } \\
\text { e o conhecimento sobre os } \\
\text { tipos de instituições financei- } \\
\text { ras da cidade de Monte Car- } \\
\text { melo, MG. }\end{array}$ & $\begin{array}{l}\text { A pesquisa abordou as principais diferenças dos bancos convencionais } \\
\text { e o cooperativismo de crédito na cidade de Monte Carmelo, MG. Confor- } \\
\text { me dados apresentados, a grande maioria da amostra da pesquisa é as- } \\
\text { sociada em alguma cooperativa de crédito, sendo a principal a SICOOB } \\
\text { ARACOOP, na qual se deu a análise. Levou-se em consideração ainda } \\
\text { que essas pessoas, além de serem clientes da cooperativa, recomen- } \\
\text { dam às demais pessoas do município o serviço oferecido. A conclusão } \\
\text { é que as cooperativas apresentam menos serviços que os bancos con- } \\
\text { vencionais, porém, oferecendo taxas, juros e tarifas menores, além do } \\
\text { atendimento diferenciado que elas prestam. }\end{array}$ \\
\hline
\end{tabular}

Fonte: elaboração das autoras.

Teoria e Evidência Econômica - a. 26, n. 55, p. 244-271, jul./dez. 2020 
Os estudos correlatos analisaram a importância das cooperativas de crédito e a contribuição no desenvolvimento dos locais onde elas atuam. Nesses estudos, os autores chegaram à conclusão de que as cooperativas de crédito são peças fundamentais para o desenvolvimento das regiões onde atuam. Diante disso, acredita-se que verificar a influência da utilização dos créditos específicos para o setor de agronegócios, oferecidos pelas cooperativas de crédito, no desenvolvimento das propriedades com maior ênfase, poderá trazer maiores conclusões sobre como elas atuam no desenvolvimento de pequenos municípios e no agronegócio local.

Discorrida a revisão de literatura utilizada para realização deste estudo, na seção seguinte, são apresentados os procedimentos metodológicos adotados para alcançar o objetivo proposto.

\section{Procedimentos metodológicos}

Gil (1999, p. 64) menciona que o delineamento da pesquisa “[...] considera o ambiente em que são coletados os dados, bem como as formas de controle das variáveis envolvidas". Quanto à abordagem do problema, o presente estudo terá abordagem quali-quantitativa no desenvolvimento, o objetivo é mensurar o progresso das propriedades rurais após a procura do crédito, levando em conta o valor concedido pela cooperativa, os custos da propriedade, seus recebimentos e sua produção. Buscaram-se dados fornecidos pela instituição, como relatórios, demonstrações e dados do período, em que se evidenciam as movimentações dos trabalhadores da área rural dentro da entidade cooperativa.

Por isso, foi utilizado o método quantitativo, que, segundo Diehl e Tatim (2004), diferencia-se pela utilização da quantificação na coleta e também no tratamento das informações por meio de procedimentos estatísticos, com os objetivos de apresentar resultados e minimizar distorções ao efetuar a análise e a interpretação, assegurando as interpretações com base nas informações expostas. A partir da análise de documentos e controles internos, evidenciam-se as variações encontradas.

Em seguida, investigaram-se quais fatores podem ter auxiliado ou dificultado o processo de desenvolvimento dos negócios dos agricultores, levando em conta as opiniões e os relatos de suas ações como gestores e proprietários, identificar se houve algum fator determinante que possa interferir nos resultados da pesquisa, como, por exemplo, os fenômenos naturais. Tais informações foram buscadas na 
cooperativa, reunindo relatos de seus gestores referentes aos produtos e serviços disponibilizados para os agricultores. Para Richardson (1999), uma abordagem qualitativa de um problema, além de ser uma opção do investigador, justifica-se também, sobretudo, por ser uma forma adequada para entender a natureza de um fenômeno social.

Quanto aos objetivos, a pesquisa é classificada como exploratória e explicativa. No desenvolvimento, foi necessária a coleta de dados referentes aos trabalhos realizados pelos trabalhadores, buscando informações sobre o proprietário, sua família e sua propriedade. Outrossim, efetuou-se a coleta de dados na instituição, a fim de fazer comparações e levantamentos, buscando compreender e apresentar em dados a participação dos agricultores dentro de uma cooperativa de crédito. Devido a isso, esse projeto tem caráter exploratório, que, conforme Diehl e Tatim (2004, p. 53), "tem como objetivo proporcionar maior familiaridade com o problema, com vistas a torná-lo mais explícito ou a construir hipóteses”. Já Richardson (1999) diz que a pesquisa exploratória geralmente envolve a aplicação de questionário pouco estruturado, com o objetivo de rever o plano de pesquisa para continuar em um estudo mais aprofundado em relação ao tema.

Pesquisas explicativas preocupam-se, principalmente, em reconhecer os fatores que influenciam a ocorrência de determinadas situações (GIL, 1999). Para entender a participação das instituições em uma propriedade rural, é necessário analisar vários resultados vindos antes e depois do fato gerador, que é a liberação do crédito, de forma detalhada. Apesar de ser mais voltado à pesquisa exploratória, o projeto possui traços de pesquisa explicativa, por exigir profundidade em alguns assuntos abordados para fortalecer o desenvolvimento e as conclusões. É caraterizada como exploratória por não possuir materiais tratando dessa veia na relação entre agricultura e cooperativismo.

No que se refere aos procedimentos, trata-se de uma pesquisa de levantamento e pesquisa documental. A pesquisa documental tem como principal caraterística a coleta de dados unicamente em documentos, escritos ou não, definidos como fonte primária, que podem ser analisados no momento ou depois que ocorre o fato (MARCONI; LAKATOS, 1999). Isso posto, realizou-se a observação e o estudo de documentos que relatem um histórico de movimentações realizadas na propriedade, antes e depois da aplicação do(s) crédito(s) concedido(s) pela instituição e solicitado pelo agricultor, além de relatórios, possíveis de liberação por parte da instituição, 
em que salienta a representatividade da classe rural nos seus resultados diários, mensais ou anuais.

Por sua vez, o levantamento, ou surveys, é definido pela interrogação direta das pessoas que entram nas delimitações definidas pelos pesquisadores, resultando em um censo. A maioria dos levantamentos não contempla todos os participantes da população estudada (GIL, 1999). A coleta de dados deu-se efetivamente pela aplicação de questionários a associados, que, de forma voluntária, participaram da pesquisa. Ademais, entrevistou-se o auditor da cooperativa participante da amostra. O roteiro de entrevista era composto por perguntas abertas e fechadas, elaboradas com base na revisão literária efetuada.

A fim de alcançar o objetivo proposto por esta pesquisa, o qual é discutir a importância das cooperativas de crédito para a produção agrícola, os estudos serão realizados em uma cooperativa de crédito da região que abrange e atende agricultores de diversos portes das cidades de Flor do Sertão, São Miguel do Oeste, Guaraciaba, São José do Cedro e região. A escolha da cooperativa deve-se ao fato de ser uma instituição com raízes na agricultura e por nortear suas ações em prol dos agricultores da região onde se encontra, trabalhando para desenvolver produtos e serviços voltados tanto às pequenas quanto às grandes propriedades rurais.

A escolha da região em que a pesquisa será desenvolvida com os agricultores deu-se por serem pequenos municípios da região que possuem concentração de diferentes atividades e de várias intensidades no meio rural, contribuindo significativamente para a economia do local, e por possuírem em seu território no mínimo uma instituição de crédito operante.

Neste trabalho, o estudo está direcionado para duas áreas em específico, rural e cooperativo, devido à grande concentração de cooperativas com produtos e serviços direcionados ao meio rural e às propriedades rurais de vários tamanhos e com produções variadas, apresentando um grande campo para pesquisa, desenvolvimento e conclusão.

\section{Análise e interpretação dos dados}

Nesta seção, serão apresentados dados referentes à pesquisa feita para identificar a influência da utilização dos créditos específicos para o setor de agronegócios, oferecidos pelas cooperativas de crédito, no desenvolvimento das propriedades, esta efetuada com agricultores e uma cooperativa de crédito. 


\section{Caracterização da amostra pesquisada}

O presente estudo se deu através de pesquisa realizada entre agricultores de pequeno, médio e grande porte de municípios do extremo oeste de Santa Catarina, onde a agricultura é significante para o desenvolvimento. Além disso, foram aplicados questionários aos responsáveis pela liberação do crédito rural de duas cooperativas de crédito que atuam na região que abrange e atende agricultores de diversos portes das cidades de Flor do Sertão, São Miguel do Oeste, Guaraciaba, São José do Cedro e região. E, complementando, foi efetuada entrevista ao auditor de uma das cooperativas de crédito. Com as devidas informações, foram identificadas a importância e a influência do cooperativismo de crédito para com o setor agrícola, bem como os benefícios que estas trazem no desenvolvimento da agricultura local.

A pesquisa foi aplicada em forma de questionário a 104 agricultores dos municípios da região do extremo oeste catarinense. Nessa amostra, a faixa etária das pessoas que vivem da agricultura deu-se pela grande quantidade de agricultores entre 20 e 30 anos de idade, cerca de $65 \%$ do total, estes já sendo sucessores das propriedades. Dos quais, $41,3 \%$ possuem curso superior completo e $33,7 \%$ ainda estão na graduação. Percebe-se que mais de $70 \%$ da amostra pesquisada são proprietários rurais com ensino superior, buscando o desenvolvimento próprio e incentivo. Uma pequena parcela ainda é dos que não tiveram tantas oportunidades e não possuem a conclusão do ensino fundamental, perfazendo $10,6 \%$ da amostra total.

Na região onde ocorreu a aplicação do estudo, o percentual de propriedades de grande porte, com mais de 15 hectares, é bem maior do que as consideradas pequenas propriedades, inferiores a 15 hectares, $48 \%$ do total. Na maioria delas, há 3 a 4 pessoas compondo o grupo familiar. É notório que o desenvolvimento vem ocorrendo cada vez mais, principalmente nos pequenos agricultores familiares.

Buainain (2006) salienta a importância da agricultura familiar, que ocupa um vultoso espaço no desenvolvimento sustentável do país, pela sua contribuição econômica. No Brasil, há mais de 4 milhões de estabelecimentos familiares rurais. A renda do setor responde por 33\% do Produto Interno Bruto (PIB) agropecuário e por $74 \%$ da mão de obra empregada no campo. O desenvolvimento vem ocorrendo cada vez mais, principalmente nos pequenos agricultores familiares. No Gráfico 1 , apresenta-se quais as principais atividades rurais desenvolvidas pela amostra. 
Gráfico 1 - Principal atividade desenvolvida na propriedade

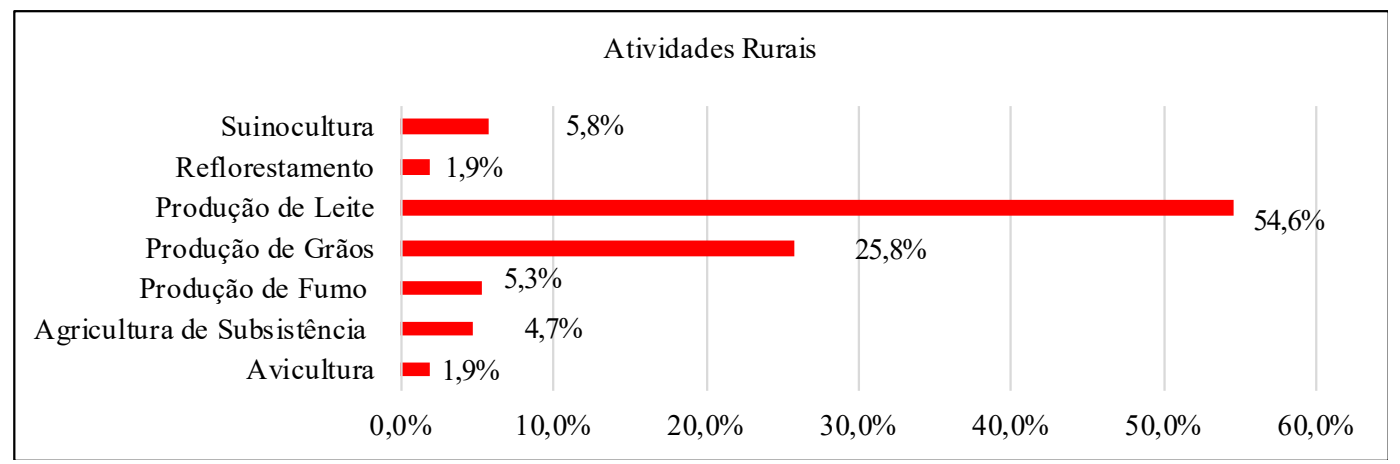

Fonte: dados da pesquisa.

Com o desenvolvimento da agricultora, pequenos produtores vêm investindo no crescimento de suas propriedades. Conforme Gráfico 1, vê-se que a região onde se deu a pesquisa tem como atividade principal a produção de leite. Observa-se que mais de 50\% do total trabalham com a produção leiteria, além claro, na maioria dos casos, da agricultura, que vai além de apenas uma atividade. Muitos agricultores desenvolvem diversas culturas de vegetais e grãos, criação de animais e agricultura de subsistência. Os achados de Porto e Ferreira (2014) apresentam que cerca de $44 \%$ dos cooperados possuem apenas uma atividade principal de sustento, visto que para a maioria a atividade principal não é suficiente para subsidiar econômica e financeiramente a família.

De acordo com dados da pesquisa, 83,7\% desses agricultores são associados em alguma cooperativa de crédito que atua na região, muitos deles buscando o crescimento de sua propriedade e novas oportunidades no cenário em que se encontram. Diante da amostra apresentada, foram coletados dados em que esses agricultores relatam a participação e a importância das cooperativas de crédito na liberação de financiamentos e empréstimos, auxiliando na expansão de suas propriedades e em melhores condições de vida.

\section{Créditos específicos mais utilizados pela área rural}

Conforme relatório da OCB (2018), de forma nacional, as cooperativas totalizavam 6.828 organizações em 2018, sendo que, destas, 909 cooperativas pertencem ao ramo do crédito. Destaca-se, ainda, que $34 \%$ do total de operações realizadas 
abarcam o ramo de crédito. Tal fato evidencia a importância dessas organizações no que se referem ao acesso a recursos que buscam fomentar as atividades rurais.

De acordo com o Banco Central do Brasil (2019), existem quatro modelos de incentivos oferecidos para o agricultor: de custeio, que são destinados às despesas relacionadas à produção até a fase da colheita; de investimento, voltados para bens e serviços com longa durabilidade; de comercialização, que têm a finalidade de garantir ao agricultor e às cooperativas recursos e condições que auxiliem na comercialização dos produtos no mercado; e de industrialização, que vêm com finalidade de valorizar a produção e gerar mais renda aos seus beneficiários. As quatro modalidades beneficiam pessoas físicas, jurídicas e também as cooperativas rurais que intermediam a disponibilidade do crédito.

Os investimentos contam com recursos do Banco Nacional de Desenvolvimento Econômico e Social (BNDES), poupança rural, Letras de crédito do agronegócio e depósitos à vista. E são oferecidos por cooperativas de crédito, bancos e instituições financeiras autorizadas a operar com essa modalidade. $O$ crédito rural possui normas aprovadas pelo Conselho Monetário Nacional (BACEN, 2019).

A Secretaria Política Agrícola (SPA) é o órgão que acompanha os movimentos dos incentivos rurais oferecidos, realizando a divulgação de relatórios mensais, classificados por safra, oferecendo dados sobre a utilização dos incentivos por todo o país. Segundo o último relatório, referente à safra 2018/2019, a modalidade de custeio foi a mais contratada, registrando 99.095 milhões, um aumento de $7 \%$ em relação à safra de 2017/2018 (BRASIL, 2019).

Segundo o relatório de desempenho do crédito rural, emitido em 2019, o montante de incentivos liberados na safra 2018/2019 foi de 99.095 milhões; e, em todas as modalidades, o Sul registra a maior porcentagem de contratações de incentivos. Salienta-se que $83 \%$ dos custeios pecuários liberados no país, na última safra, foram destinados a produção e compra de bovinos, já nas contratações de custeio agrícola, a soja se sobressai, recebendo $44 \%$ do valor liberado para esse segmento (BRASIL, 2019). De acordo com o Gráfico 1, 54,8\% dos pesquisados relatam que sua atividade principal é a produção de leite, seguida dos grãos com $26,9 \%$, percentuais que refletem os dados evidenciados pelo relatório de desempenho do crédito rural. 


\section{Efeitos gerados após a injeção do crédito no desenvolvimento das propriedades}

Conforme o Ministério da Agricultura, Pecuária e Abastecimento (BRASIL, 2017), o governo federal vem garantindo a segurança dos agricultores, além da liberação de crédito mais barato através do Programa de Fortalecimento da Agricultura Familiar (Pronaf), para a ampliação e a modernização das estruturas de produção das propriedades rurais, em trabalho conjunto com as cooperativas de crédito, visando geração de renda, desenvolvimento e melhora do uso da mão de obra familiar.

O Banco Central do Brasil (Bacen) determina algumas linhas de crédito já definidas, além de taxas, prazos, formas de pagamento e documentos obrigatórios para a concessão de empréstimos, tais determinações estão descritas no Manual de Crédito Rural (MCR), o qual é seguido para todas as instituições que trabalham com crédito rural, mais especificamente com recursos controlados. Dessa forma, as cooperativas de crédito entram no cenário, intermediando o acesso à liberação de crédito para os agricultores associados. Na pesquisa, entre mais de 100 agricultores de diversos municípios do extremo oeste catarinense, o percentual daqueles que são adeptos ao cooperativismo de crédito ultrapassa 80\%; destes, mais de $50 \%$ já adquiriu algum modelo de empréstimo ou financiamento intermediado pelas cooperativas de crédito.

No que se refere às cooperativas de crédito, elas são movidas por ações diferenciadas voltadas à sociedade, trabalham disponibilizando um atendimento que simplifique os processos burocráticos, com qualidade e comprometimento para com seus associados, buscando sempre o melhor acesso a melhores linhas de crédito para o desenvolvimento das atividades de seus cooperados. Segundo Menezes e Lajus (2015), o cooperativismo de crédito pode ser usado como um meio de apoio, promovendo a disponibilização de recursos a custos mais baixos em negócios com maior identificação do seu local de abrangência.

Relatos de agricultores que responderam à pesquisa apontam que o cooperativismo de crédito é indispensável na agricultura, quando dado a agricultores que necessitam de empréstimos e financiamentos para colocar sua propriedade à frente, melhorando seus rendimentos e suas condições de vida, possibilitando taxas de juros menores que as de bancos convencionais, melhores prazos para pagamento da dívida. Sabe-se que a aquisição de maquinário e implementos para 
uso na agricultura é de custo alto, mas necessário, e poucos agricultores possuem capital próprio para adquiri-los, dessa maneira, o cooperativismo de crédito entra para intermediar e auxiliar a aquisição dos bens de seus associados. A finalidade do recurso captado junto à instituição financeira é apresentada no Gráfico 2.

Gráfico 2 - Destinação dos recursos liberados pelas cooperativas

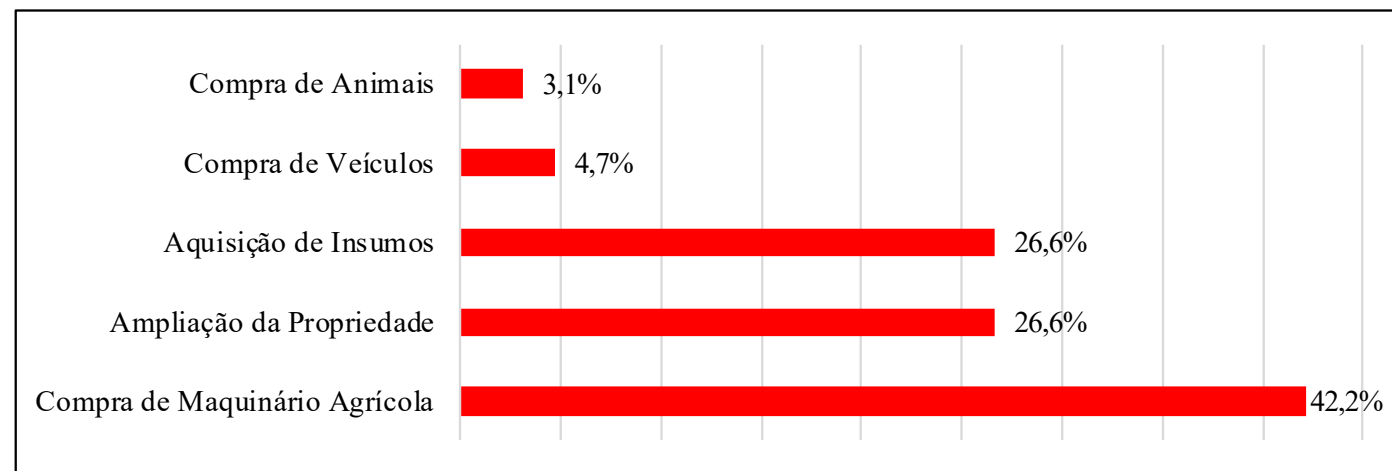

Fonte: dados da pesquisa.

Conforme Gráfico 2, denota-se que há grande destinação dos créditos rurais para a aquisição de maquinários agrícolas e de insumos e, consequentemente, a ampliação da propriedade. Produtores rurais sofrem no desemprenho de suas atividades, visto que há períodos em que o preço de venda dos produtos despenca de maneira exorbitante, e também períodos em que o clima não colabora no desenvolvimento da produção, sendo no plantio ou na colheita, afetando o desenvolvimento e o sustento dos agricultores, independentemente da cultura que cultivada ou da atividade que desempenha.

Segundo os achados de Andrade e Alves (2013), na agricultura familiar, encontram-se vários obstáculos, entre eles a questão do desenvolvimento e do repasse de tecnologias adequadas para os agricultores, capacitação, financiamento, políticas públicas voltadas para a transformação estrutural do setor, entre outros.

Diante dos dados da pesquisa efetuada, percebe-se que o agricultor vem buscando cada vez mais o desenvolvimento da propriedade, a aquisição de maquinários, na maioria das vezes, dotados de tecnologia, pois, nos dias de hoje, há maquinários para tudo, desde o preparo da terra para o plantio até a colheita do produto. Com isso, depois da injeção de investimento na agricultura, é muito mais evidente o desenvolvimento que vem ocorrendo nas propriedades rurais, não só da região de abrangência desta pesquisa, mas de todo o país. 


\section{A importância das cooperativas de crédito no cenário do agronegócio}

O meio rural se destaca pela longa história e pela estabilidade dos produtores, $54,8 \%$ dos pesquisados declararam que possuem o seu negócio há mais de vinte anos. Mesmo com todas as adversidades que afetam as propriedades, houve resistência e inovação, com a implementação de novas tecnologias, principalmente com maquinários e novos produtos desenvolvidos pelo mercado. As cooperativas sempre buscaram acompanhar esse processo de desenvolvimento constante vivido pelos cultivadores, procurando desenvolver e oferecer produtos que supriam as necessidades identificadas no ramo, como, por exemplo, seguros para plantações, animais, entre outros.

A especialização foi apontada pelos pesquisados como meio fundamental para a continuidade das propriedades. Com o crescimento do agronegócio, tornou-se cada dia mais necessário conhecimento apurado sobre gestão, fluxo de caixa, noções econômicas, comerciais, agrícolas, entre muitos outros pontos que fazem a diferença quando inseridos no desenvolvimento do agronegócio, visto que a agricultura é cercada por créditos facilitados, que podem ser tanto um auxílio quanto uma má escolha. Sem o planejamento, a tendência é de que se tenha dívidas maiores que os lucros, reduzindo a atividade até tornar-se insustentável.

A predominância da atividade leiteira, na região pesquisada, revela que os produtores passam por muitas variações, pois o valor pago mensalmente pelo litro de leite é afetado diretamente pelas movimentações do mercado. A redução mais expressiva registrada no ano de 2019 foi em Santa Catarina, decaindo 13\% em julho, comparado ao mês anterior (SANTOS, 2019). Levando em conta essa variação constante, uma das cooperativas pesquisadas, que hoje conta com aproximadamente $50 \%$ de associados agricultores no seu quadro social, evidenciou que os maiores montantes de custeios agrícolas liberados são destinados à pecuária.

Quanto à contribuição das instituições para o meio rural, foram registrados vários pontos de vista. Segundo o questionário aplicado, 83,7\% possuem contas correntes ativas em alguma cooperativa de crédito da região; ainda, 55,8\% dos pesquisados revelam que possuem empréstimos, crédito concedido sem vinculação com a aquisição de algum bem, e 50\% possuem financiamentos, crédito liberado para a compra de algo específico, evidenciando a continuidade da produção no meio rural, buscando o melhoramento com maquinário e investimentos. 
Mesmo com esses dados, que ressaltam o lado positivo da relação entre cooperativa e agricultor, o questionário registrou vários relatos expondo as diferentes opiniões sobre a concessão de crédito pelas cooperativas. Alguns veem o crédito como uma forma de viabilizar as aquisições para o desenvolvimento, outros acreditam que o crédito é, sim, algo positivo, porém deve ser utilizado com cautela, com planejamento; por fim, alguns relatam ver desvantagem por conta dos juros praticados e que preferem buscar a autossustentabilidade, sem subsídios. O auditor entrevistado, salienta que se deve levar em conta o fato de que muitos incentivos de créditos facilitados, oferecidos pelas cooperativas, já possuem predefinição regulamentada pelo governo no momento da criação das leis que regem os custeios agrícolas, algumas leis definem filtros para a liberação do crédito, impossibilitando que a cooperativa tenha maior flexibilidade com esse produto. Todas as liberações de créditos agrícolas, subsidiados pelo governo, possuem o Manual de Crédito Ru-

ral, que reúne as normas aprovadas pelo Conselho Monetário Nacional e do Banco Central do Brasil (BACEN, 2019).

Por meio de questionário aplicado, uma das cooperativas destaca a flexibilidade e a variedade oferecidas pelos seguros agrícolas. Esse produto conta com uma ampla variedade de coberturas e valores que tem o objetivo de atender as preocupações dos produtores, as cooperativas realçam o forte companheirismo desde 0 início de suas atividades, e o tratamento interpessoal, em que priorizam os associados. Destacam, também, a participação de todos os associados nas sobras anuais das cooperativas, que, conforme Staub, Fuhrmann e Staub (2016), são distribuídas levando em consideração as movimentações registradas em cada conta corrente.

\section{Conclusões e recomendações}

O trabalho teve como propósito identificar qual a influência e a relevância, levando em conta produtos e serviços, das cooperativas de crédito para os agricultores e as propriedades rurais, de modo que o objetivo geral e os objetivos específicos foram atingidos, visto que foi possível identificar e ressaltar pontos importantes que evidenciam a relação entre as cooperativas de crédito e os produtores rurais da região estudada. Diante disso, foi analisada a história das cooperativas e reconhecida a conexão firmada há tempos entre cooperativas de crédito e a área rural, além de ressaltar a visão dos agricultores quanto às suas atividades junto às instituições e compreender a origem, o processo e a normatização dos incentivos agrícolas. 
Quanto ao primeiro objetivo, que consistia em evidenciar a caracterização da amostra pesquisada, houve uma pesquisa abrangendo 104 propriedades rurais da região do extremo oeste catarinense. Com esta pesquisa, observou-se que grande parte dos pesquisados, 65\% especificamente, possui idade entre 20 e 30 anos, evidenciando a intensão de continuidade no meio rural. Também se evidenciou a busca por desenvolvimento e investimento em novas tecnologias pelos pesquisados.

As instituições, nas quais também foram aplicados questionários, disponibilizaram informações que evidenciaram os créditos mais utilizados por seus associados, enfatizaram a relação com a área rural, que possui uma longa e sólida história. Todas as cooperativas pesquisadas salientaram algumas vantagens disponibilizadas aos agricultores, como seguros, créditos específicos e o direito ao recebimento das sobras anuais. Realçam o fato de possuírem em seu quadro social um número expressivo de colaboradores rurais, destacando o atendimento pessoalizado como um dos diferenciais no mercado.

O segundo objetivo buscava salientar os créditos específicos mais utilizados, com isso, o questionário aplicado aos agricultores apresentou dados que, comparados às pesquisas realizadas em nível nacional, por órgãos governamentais, refletem resultados parecidos. A região possui maior produção pecuária, principalmente na área leiteira, seguida dos grãos, mesma ordem de produtividade apontada no relatório de desempenho do crédito rural, que expõe dados em nível de país. Conclui-se que o subsídio que apresenta maior liberação é o pecuário, seguido do custeio agrícola, que é destinado, por exemplo, ao cultivo de milho e soja. $\mathrm{O}$ relatório também aponta o estado de Santa Catarina como um dos que mais efetua contratações de subsídios.

Em seguida, com o intuito de analisar os efeitos gerados após a injeção do crédito no desenvolvimento de propriedades, foi possível perceber que há a participação direta do governo na regulamentação e fiscalização das cooperativas e, principalmente, dos incentivos rurais que estão dispostas no Manual de Crédito Rural. As instituições atuam como intermediadoras da liberação do crédito subsidiado pelo governo, além disso, procuram expandir e incluir em seu portfólio produtos e serviços destinados a auxiliar e mitigar as necessidades identificadas no meio rural ao longo do tempo, sem deixar de desenvolver produtos e serviços direcionados também aos associados de diferentes áreas.

Tornou-se evidente a procura dos cultivadores por desenvolvimento, capacitação e tecnologia, a fim de dar continuidade e desenvolver suas atividades. A aceitação e a procura pelas cooperativas foram outro ponto salientado na análise, 83,7\% dos 
pesquisados informaram possuir conta em alguma cooperativa de crédito da região, e 50\% destes declararam já ter adquirido algum financiamento ou empréstimo.

Com o propósito de demonstrar a importância das cooperativas de crédito no cenário do agronegócio, o questionário revelou a estabilidade dos produtores, pois $54,8 \%$ dos produtores possuem sua propriedade há mais de vinte anos. Além disso, a pesquisa reuniu a opinião dos agricultores sobre a relevância das cooperativas em suas propriedades e foram registrados muitos pontos de vista. Alguns agricultores reconhecem a importância dos produtos e serviços oferecidos e relatam perceber o desenvolvimento de suas atividades com a busca pelo crédito nas instituições, outros salientam a importância de uma boa gestão e de planejamento para transformar o crédito contratado em lucros para o negócio, por fim, alguns pesquisados relataram que preferem não utilizar subsídios por verem como dívidas inviáveis e buscam desenvolver uma atividade autossustentável. Conclui-se que a cooperativa pode desempenhar um papel positivo, assim como pode tornar-se o antagonista em relação à continuidade e à prosperidade das atividades rurais, o que pode definir esse papel é as escolhas feitas, posteriormente às contratações, pelo gestor da atividade.

Como sugestão, para maior entendimento da área estudada, torna-se interessante a análise profunda em uma propriedade rural em que o agricultor utiliza os subsídios disponibilizados pelas cooperativas, avaliando seu histórico de atividades, custos, despesas, valores de vendas praticados, identificando os controles utilizados e o direcionamento dos créditos adquiridos com terceiros. Ainda, a verificação e a comparação do PIB entre regiões que possuem uma cooperativa de crédito e regiões que não são atendidas por essas instituições podem acentuar a importância das atividades cooperativas para a economia de uma região. Por fim, outro ponto possível de avaliação é a real aderência dos associados às cooperativas, segregando por número de movimentações, definindo qual o percentual de associados ativos, com movimentação constante, e associados neutros, com movimentações mínimas, buscando compreender os motivos das variações resultantes.

Em síntese, conclui-se que, com a junção de dados e relatos de ambos os lados abordados, o trabalho auxiliou na identificação de pontos que explicam a proximidade e a união de duas áreas que possuem grande influência na região e seguem prosperando. As duas atividades seguiram se desenvolvendo, o setor rural movido pelo próprio comércio e pela economia, e o setor cooperativo, também, pelas variações econômicas, para atender as necessidades de seus associados, buscando auxiliar 
no desenvolvimento das atividades. Criadas por agricultores, as cooperativas registram um número significativo de movimentações e negociações nessa área. Essa parceria, como consequência, traz benefícios à região que a instituição abrange, lucrando indiretamente, promovendo o desenvolvimento econômico e social do local.

\title{
Importance of credit cooperativism for the development of agribusiness
}

\begin{abstract}
The aim of this paper is to identify the relevance of products and services offered by credit unions to the agribusiness sector in the development of properties, in addition to identifying the effects generated after the injection of specific credits in the development of rural properties, processes and the cooperative view of farmers. The collected data evidenced that the credit cooperative presents itself as a considerable alternative for the development of the rural properties and consequently the regional development. Greater demand is given for financing and loans by farmers to continue the development of their properties, investing in crops and implements.
\end{abstract}

Keywords: credit unions; farmers; regional development; rural properties.

\section{Importancia del cooperativismo de crédito para el desarrollo de la agronegocios}

\section{Resumen}

Se buscó identificar la relevancia de los productos y servicios que ofrecen las cooperativas de ahorro y crédito al sector agroindustrial en el desarrollo de predios, además de identificar los efectos que se generan luego de la inyección de créditos específicos en el desarrollo de predios rurales, procesos y visión cooperativa de agricultores. Los datos recolectados evidenciaron que la cooperativa de crédito se presenta como una alternativa considerable para el desarrollo de las propiedades rurales y consecuentemente el desarrollo regional. Se da mayor demanda de financiamiento y préstamos por parte de los agricultores para continuar el desarrollo de sus propiedades, invirtiendo en cultivos e implementos.

Palabras clave: las cooperativas de crédito; agricultores; desarrollo regional; finca rústica. 


\section{Referências}

ANDRADE, Marta Cleia; ALVES, Daniela Cristina. Cooperativismo e agricultura familiar: um estudo de caso. Revista de Administração IMED, 2013.

BANCO CENTRAL DO BRASIL. Participação das cooperativas no mercado de crédito. 2019. Disponível em: https://www.bcb.gov.br/conteudo/relatorioinflacao/EstudosEspeciais/Participacao_cooperativas_mercado_credito.pdf. Acesso em: 15 maio 2019.

BANCO CENTRAL DO BRASIL. Cooperativas de crédito e seus impactos sociais. 2019. Disponível em: https://www.bcb.gov.br/pre/microfinancas/arquivos/horario_arquivos/trab_50.pdf. Acesso em: 02 maio 2019.

BANCO CENTRAL DO BRASIL. Participação das cooperativas no mercado de crédito. 2019. Disponível em: https://www.bcb.gov.br/estabilidadefinanceira/creditorural. Acesso em: 15 set. 2019.

BANCO CENTRAL DO BRASIL. Manual de crédito rural. 2019. Disponível em: https://www3. bcb.gov.br/mcr/completo. Acesso em: 10 out. 2019.

BRASIL. Lei no 5.764, de 16 de dezembro de 1971. Define a Política Nacional de Cooperativismo, institui o regime jurídico das sociedades cooperativas, e dá outras providências. Brasília, DF, 1971. Disponível em: http://www.planalto.gov.br/ccivil_03/LEIS/L5764.htm. Acesso em: 21 maio 2019.

BRASIL. Lei nº 11.326, de 24 de julho de 2006. Estabelece as diretrizes para a formulação da Política Nacional da Agricultura Familiar e Empreendimentos Familiares Rurais. Brasília, DF, 2006. Disponível em: http://www.planalto.gov.br/ccivil_03/_Ato2004-2006/2006/Lei/L11326.htm. Acesso em: 21 maio 2019.

BUAINAIN, Antônio Márcio. Agricultura familiar, agroecologia e desenvolvimento sustentável: questões para debate. Brasília, DF: IICA, 2006.

CARNEIRO, Maria José. Política pública e agricultura familiar: uma leitura do Pronaf. p. 70-82, abril 1997.

COSTA, Leonardo Ferreira da; VALDISSER, Cássio Raimundo. Análise do diferencial de uma cooperativa de crédito em relação a um banco comercial na cidade de Monte Carmelo -MG. Minas Gerais, 2017.

DIEHL, Astor Antônio; TATIM, Denise Carvalho. Pesquisa em ciências sociais aplicadas: métodos e técnicas. Pearson Brasil, 2004.

FARIAS, Greice. Sindicato dos trabalhadores rurais 40 anos de lutas e conquistas. São Miguel do Oeste: Edição Da Autora, 2010.

FORTUNATO, João Paulo. A importância do capital social e sua remuneração nas cooperativas de crédito. 2017. Disponível em: https://www.blogsicoobcredpit.com.br/cooperativismo/a-importancia-do-capital-social-e-sua-remuneracao-nas-cooperativas-de-credito/. Acesso em: 20 abr. 2019.

GIL, Antonio Carlos. Métodos e técnicas de pesquisa social. São Paulo: Editora Atlas S.A, 1999.

GUISO, Luigi; SAPIENZA, Paola; ZINGALES, Luigi. Does local financial development matter? The Quarterly Journal of Economics, v. 119, n. 3, p. 929-969, 2004. 
MARCONI, Marina de Andrade; LAKATOS, Eva Maria. Técnicas de pesquisa. São Paulo: Editora Atlas S.A., 1999.

MEINEN, Ênio. Cooperativismo financeiro: virtudes e oportunidades. Brasília, DF: Editora Confebras, 2016.

MENEZES, Celso Marque; LAJUS, Maria Luiza de Souza. Cooperativismo de crédito e desenvolvimento. Revista Economia e Desenvolvimento, 2015.

BRASIL. Ministério da Agricultura, Pecuária e Abastecimento. Plano Safra da agricultura familiar 2017/2020. 2017. Disponível em: http://www.mda.gov.br/sitemda/plano-safra-da-agricultura-familiar-20172020. Acesso em: 15 abr. 2019.

BRASIL. Ministério da Agricultura, Pecuária e Abastecimento. Desempenho do crédito rural. 2019. Disponível em: http://www.agricultura.gov.br/assuntos/politica-agricola/copy_of_arquivos/ Safra20192020JulhoaAgosto.pdf. Acesso em: 15 out. 2019.

MORAES, J. L. de. A.; MEDEIROS, A. M. de; MATTE JUNIOR, A. A. Resultados do uso do crédito rural (PRONAF) pelos agricultores familiares de Santo Antônio da Patrulha-RS. Estudos do CEPE, p. 64-80, 2018.

MISSIO, F. J.; JAYME JR., F. G.; OLIVEIRA, A. M. H. C. Desenvolvimento financeiro e crescimento econômico: teoria e evidência empírica para os estados brasileiros (1995-2004). Belo Horizonte: Cedeplar, 2010. (Textos para Discussão, n. 379). Disponível em: http://www.cedeplar.ufmg. br/Pesquisas/Td/Td\%20379.Pdf. Acesso em: 22 maio 2019.

MUMIC, Bianca; AGUIAR, Karoline Aparecida Pimenta; LIVRAMENTO, Darlan Einsten do. A importância do associativismo na organização de produtores rurais. Revista de Iniciação Científica da Libertas, v. 5, n. 1, 2016.

OÑATE, Carlos Andrés; LIMA, Roberto Arruda de Souza. Importância das cooperativas de crédito para fornecedores de cana-de-açúcar: um estudo de caso. Revista de Economia e Sociologia Rural, v. 50, n. 2, p. 301-318, 2012.

ORGANIZAÇÃO DAS COOPERATIVAS BRASILEIRAS. História do sistema OCB. Disponível em: https://www.ocb.org.br/historia-do-sistema-ocb. Acesso em: 22 out. 2019.

ORGANIZAÇÃO DAS COOPERATIVAS BRASILEIRAS. Anuário do Cooperativismo Brasileiro 2019. Disponível em: https://www.ocb.org.br/publicacao/53/anuario-do-cooperativismo-brasileiro-2019. Acesso em: 15 maio 2019.

PINHEIRO, Marcos Antonio Henriques. Cooperativas de crédito: história da evolução normativa no Brasil. Brasília, DF: BCB, 2008.

PINHO, Diva Benevides; PALHARES, Valdecir Manuel Affonso. O cooperativismo de crédito no Brasil: do século XX ao século XXI. Santo André: ESETec Editores Associados, 2004.

PORTAL DO COOPERATIVISMO FINANCEIRO. História do cooperativismo de crédito no Brasil. 2016a. Disponível em: https://cooperativismodecredito.coop.br/cooperativismo/historia-do-cooperativismo/historia-no-brasil/. Acesso em: 29 mar. 2019.

PORTAL DO COOPERATIVISMO FINANCEIRO. Os pioneiros de Rochdale. 2016b. Disponível em: https://cooperativismodecredito.coop.br/cooperativismo/historia-do-cooperativismo/os-pioneiros-de-rochdale/. Acesso em: 25 abr. 2019. 
PORTO, Selomi Bermeguy; FERREIRA, Marinilde Verçosa. Cooperativismo e desenvolvimento socioeconômico: uma análise da cooperativa de crédito rural de economia solidária - Solicred. Cadernos Gestão Social, v. 5, n. 2, p. 337, 2014.

RIBEIRO, Kleber Ávila; NASCIMENTO, Deise Cristiane do; SILVA, Joelma Fabiana Barros da. Cooperativismo agropecuário e suas contribuições para o empoderamento dos agricultores familiares no submédio São Francisco: o caso da associação de produtores rurais do núcleo VI Petrolina/PE. Revista Teoria e Evidência Econômica, v. 19, n. 40, 2013.

RICHARDSON, Roberto Jarry (col.). Pesquisa social: métodos e técnicas. v. 3. 1999.

SECRETARIA DE AGRICULTURA FAMILIAR E COOPERTATIVISMO. Plano agrícola e pecuário 2013/2014. 2014. Disponível em: https:/www.gov.br/agricultura/pt-br/assuntos/politica-agricola/todas-publicacoes-de-politica-agricola/plano-agricola-pecuario/plano-agricola-e-pecuario-2013-2014.pdf/view. Aceso em: 22 out. 2019.

SANTOS, Juliana. LEITE/CEPEA: após seis meses de altas consecutivas, preço recua quase 8\% em julho. 2019. Disponível em: https://www.cepea.esalq.usp.br/br/releases/leite-cepea-apos-seis-meses-de-altas-consecutivas-preco-recua-quase-8-em-julho.aspx. Acesso em: 07 out. 2019.

SERENINI, Márcio José; MALYSZ, Sandra Terezinha. A importância da agricultura familiar na produção de alimentos. Governo do Estado. Curitiba: Cadernos PDE, 2015.

SERVIÇO NACIONAL DE APRENDIZAGEM DO COOPERATIVISMO. Dia C. Disponível em: http://diac.somoscooperativismo.coop.br/dia-c. Acesso em: 15 maio 2019.

SICOOB CECREMEF. História do cooperativismo. Disponível em: http://www.sicoobcecremef. com.br/historia-do-cooperativismo/. Acesso em: 18 abr. 2019.

STAUB, Euclides; FUHRMANN, Edson; STAUB, Lotário. Cooperativismo \& associativismo: a força coletiva em prol do bem comum. São Miguel do Oeste: Gráfica e Editora São Miguel, 2016.

ULHARUZO, Daniel Nozaki. As cooperativas de crédito como agentes de desenvolvimento local endógeno: um estudo de caso na Sicredi Pioneira RS. Porto Alegre, 2014. 